\title{
Initiating aerobic exercise with low glycogen content reduces markers of myogenesis but not mTORC1 signaling
}

Lee M. Margolis ${ }^{*} \mathbb{D}$, Marques A. Wilson, Claire C. Whitney, Christopher T. Carrigan, Nancy E. Murphy, Adrienne Hatch-McChesney and Stefan M. Pasiakos

\begin{abstract}
Background: The effects of low muscle glycogen on molecular markers of protein synthesis and myogenesis before and during aerobic exercise with carbohydrate ingestion is unclear. The purpose of this study was to determine the effects of initiating aerobic exercise with low muscle glycogen on MTORC1 signaling and markers of myogenesis.

Methods: Eleven men completed two cycle ergometry glycogen depletion trials separated by $7-\mathrm{d}$, followed by randomized isocaloric refeeding for 24-h to elicit low (LOW; $1.5 \mathrm{~g} / \mathrm{kg}$ carbohydrate, $3.0 \mathrm{~g} / \mathrm{kg}$ fat) or adequate (AD; $6.0 \mathrm{~g} / \mathrm{kg}$ carbohydrate, $1.0 \mathrm{~g} / \mathrm{kg}$ fat) glycogen. Participants then performed 80-min of cycle ergometry $(64 \pm 3 \%$ $\mathrm{VO}_{2 \text { peak }}$ ) while ingesting $146 \mathrm{~g}$ carbohydrate. mTORC1 signaling (Western blotting) and gene transcription (RT-qPCR) were determined from vastus lateralis biopsies before glycogen depletion (baseline, BASE), and before (PRE) and after (POST) exercise.

Results: Regardless of treatment, p-mTORC1 ${ }^{\text {Ser2448, }}$ p-p70S6K $K^{\text {Ser424/421 }}$, and p-rpS6 $6^{\text {Ser235/236 }}$ were higher $(P<0.05)$ POST compared to PRE and BASE. PAX7 and MYOGENIN were lower $(P<0.05)$ in LOW compared to AD, regardless of time, while MYOD was lower $(P<0.05)$ in LOW compared to AD at PRE, but not different at POST.

Conclusion: Initiating aerobic exercise with low muscle glycogen does not affect mTORC1 signaling, yet reductions in gene expression of myogenic regulatory factors suggest that muscle recovery from exercise may be reduced.
\end{abstract}

Keywords: High fat, High carbohydrate, Muscle regeneration, Endurance exercise

\section{Introduction}

Reducing muscle glycogen through sustained aerobic exercise followed by low carbohydrate, high fat feeding increases fat oxidation and decreases carbohydrate oxidation during subsequent exercise bouts [1-4]. When aerobic exercise is initiated with low glycogen, adjustments in intramuscular molecular signaling modulate changes in substrate oxidation, compared to exercising when glycogen stores are high [5]. Low glycogen

\footnotetext{
* Correspondence: lee.m.margolis.civ@mail.mil

Military Nutrition Division, U.S. Army Research Institute of Environmental Medicine, 10 General Greene Avenue, Bldg. 42, Natick, MA 01760, USA
}

availability upregulates transcription of fatty acid translocase (FAT), carnitine palmitoyl transferase 1a (CPT1a) and hydroxyacyl-CoA dehydrogenase (HADHA), which govern fatty acid uptake, transport, and oxidation [6-9]. Concurrent with transcriptional changes in fatty acid metabolism are reductions in pyruvate dehydrogenase (PDH) activity which spares glycogen by reducing carbohydrate oxidation during exercise $[10,11]$. These acute molecular adaptations to initiating aerobic exercise with low muscle glycogen persist even when carbohydrate is ingested during the exercise bout [12].

(c) The Author(s). 2021 Open Access This article is licensed under a Creative Commons Attribution 4.0 International License, which permits use, sharing, adaptation, distribution and reproduction in any medium or format, as long as you give appropriate credit to the original author(s) and the source, provide a link to the Creative Commons licence, and indicate if changes were made. The images or other third party material in this article are included in the article's Creative Commons licence, unless indicated otherwise in a credit line to the material. If material is not included in the article's Creative Commons licence and your intended use is not permitted by statutory regulation or exceeds the permitted use, you will need to obtain permission directly from the copyright holder. To view a copy of this licence, visit http://creativecommons.org/licenses/by/4.0/. The Creative Commons Public Domain Dedication waiver (http://creativecommons.org/publicdomain/zero/1.0/) applies to the data made available in this article, unless otherwise stated in a credit line to the data. 
Though performing aerobic exercise with low glycogen results in molecular adaptations that facilitate increased fat oxidation [5], this practice may compromise muscle repair and recovery $[13,14]$. Reliance on protein for oxidative purposes increases when aerobic exercise is initiated with low glycogen [13-15]. Increased use of protein for fuel appears to contribute to lower rates of muscle protein synthesis and blunted activation of the mechanistic target of rapamycin complex 1 (mTORC1) signaling cascade following exercise [13, 16, 17]. Maintaining low glycogen by adhering to a low carbohydrate, high-fat diet may also contribute to impaired muscle repair and recovery after aerobic exercise $[18,19]$. Increased concentrations of free fatty acids using lipid infusions in humans [18] or lipid-enriched media in cell culture models [19] decreases muscle protein synthesis and expression of myogenic regulatory factors, $P A X 7, M Y O D$, and MYOGENIN, thereby impairing myotube formation. Suppressed myogenesis in cell culture models suggests that increased fatty acid availability reduces muscle repair and regeneration. To the best of our knowledge, this posited mechanism has not been confirmed in humans. Furthermore, whether consuming carbohydrate during exercise initiated with low glycogen mediates the potential negative effects on myogenesis by stimulating AKT to upregulate mTORC1 signaling is unclear $[20,21]$.

The objective of this study was to examine the effects of glycogen availability on mTORC1 signaling and marks of myogenesis before and after a bout of aerobic exercise. We manipulated glycogen availability for those experiments using a glycogen depleting bout of cycle ergometry followed by high carbohydrate, low-fat or low carbohydrate, high-fat diets for the $24 \mathrm{~h}$ before the experiments. Additionally, this study examined the impact of consuming carbohydrate during a subsequent bout steady-state aerobic exercise initiated with low glycogen on post exercise mTORC1 signaling and markers of myogenesis. We hypothesized that mTORC1 signaling and myogenesis would be lower when aerobic exercise was initiated with low compared to adequate glycogen.

\section{Materials and methods}

\section{Participants}

Twelve healthy, non-obese, recreationally active men between the ages of 18-39 years were enrolled to participate in this randomized, crossover study after providing informed, written consent. Individuals were excluded from the study if they were not in good health (metabolic or cardiovascular abnormalities, gastrointestinal disorders such as kidney disease, diabetes, and cardiovascular disease or were taking medications, such as stains, corticosteroids or diabetes medication that may affect macronutrient metabolism), refused to abstain from alcohol, nicotine, and dietary supplements during the study, had musculoskeletal injuries that compromised their ability to exercise, or donated blood within 8 weeks of beginning the study. Treatment order randomization was done using a random number generator. Participants in this study were part of a larger investigation that also aimed to assess the impact of glycogen content on microRNA expression and rates of exogenous glucose oxidation during steady-state aerobic exercise (Trial registration: Carbohydrate Availability and microRNA Expression, registered 15 August 2017, https:// clinicaltrials.gov/ct2/show/NCT03250234). Results from this separate objective are reported elsewhere [12]. Data are reported on 11 of the 12 enrolled participants because we were unable to collect a baseline muscle biopsy on one participant. This study was approved by the Institutional Review Board at the US Army Medical Research and Development Command (MRDC, Fort Detrick, MD) and data collection took place at the US Army Research Institute of Environmental Medicine (USARIEM, Natick, MA), between August 2017 to May 2018.

Pre-study participant characteristics, including height (Seritex, Inc., Carlstadt, NJ, USA), body mass (WB-110A, Tanita, Tokyo, Japan), and body composition (dual energy $\mathrm{x}$-ray absorptiometry, DPX-IQ, GE Lunar Corporation, Madison, WI, USA), are reported in Table 1. Peak oxygen uptake $\left(\dot{\mathrm{VO}}_{2 \text { peak }}\right)$ was determined using a progressive-intensity cycle ergometer (Lode, BV, Netherlands) test and an indirect, open circuit respiratory system (True Max 2400, Parvomedics, Sandy, Utah, USA). Exercise intensities for protocol days were based on volunteers $\dot{\mathrm{V}}_{2 \text { peak }}$.

\section{Experimental design}

To normalize muscle glycogen between study arms, participants completed a glycogen depletion (Lode, BV, Netherlands) protocol 48-h prior to testing (Fig. 1), as previously described [12]. Participants completed 2-min of high-intensity cycling (work period) at $90 \% \mathrm{~V}_{2}$ peak, followed by a 2-min recovery period cycling at $50 \%$ $\dot{\mathrm{V}} \mathrm{O}_{\text {2peak }}$ [2]. This work-to-recovery ratio was maintained until the participant was no longer able to complete 2-

Table 1 Participant characteristics

\begin{tabular}{|c|c|}
\hline Characteristics & \\
\hline Age (yrs) & $21 \pm 4$ \\
\hline Height (m) & $1.8 \pm 0.1$ \\
\hline Weight (kg) & $83 \pm 11$ \\
\hline Body Mass Index $\left(\mathrm{kg} / \mathrm{m}^{2}\right)$ & $26 \pm 2$ \\
\hline Fat mass (kg) & $19 \pm 10$ \\
\hline Fat-free mass (kg) & $63 \pm 9$ \\
\hline$\dot{\mathrm{V}} \mathrm{O}_{2 \text { peak }}(\mathrm{mL} / \mathrm{min} / \mathrm{kg})$ & $44 \pm 4$ \\
\hline
\end{tabular}

Values are mean $\pm S D, n=11$ 


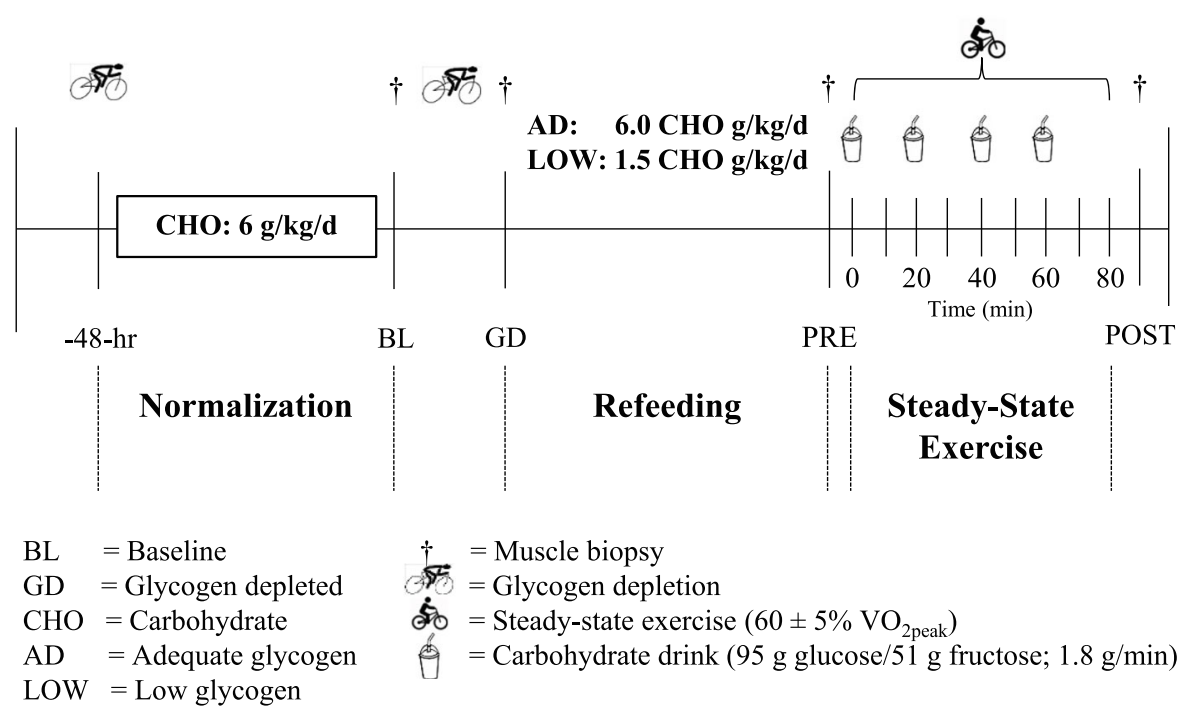

Fig. 1 Experimental design

min of cycling at $90 \% \dot{\mathrm{V}}_{2 \text { peak }}$. Cycling intensity during the work period was progressively lowered to $80 \%, 70 \%$, and $60 \% \dot{\mathrm{V}}_{2 \text { peak }}$ when the participant was unable to complete 2-min of cycling at the given workload. Once the participant could not complete 2-min of cycling at $60 \% \dot{\mathrm{VO}}_{2 \text { peak }}$, exercise was stopped. The recovery period was maintained at $50 \% \dot{\mathrm{VO}}_{2 \text { peak }}$. Participants performed two practice sessions to ensure they were familiar with the protocol before testing.

Following glycogen depletion, dietary intake was controlled to normalize glycogen status before experimental days. All food and beverages (except water, which was allowed ad libitum) were provided during this glycogen normalization phase by study dietitians, who designed and prepared meals, derived from Meals, Ready-to-Eat (MRE; Ameriqual, Evansville, IN, USA) combat rations and commercially available food items. Participants returned all food and beverage wrappers and containers to dietitians to confirm intake. During the glycogen normalization phases, intakes were the same for LOW and $\mathrm{AD}$; averaging $5.7 \pm 0.6 \mathrm{~g} / \mathrm{kg} / \mathrm{d}$ carbohydrate, $1.2 \pm$ $0.1 \mathrm{~g} / \mathrm{kg} / \mathrm{d}$ protein, and $1.0 \pm 0.1 \mathrm{~g} / \mathrm{kg} / \mathrm{d}$ fat.

Following a $10 \mathrm{~h}$ overnight fast, a baseline (BL) muscle biopsy was taken from the vastus lateralis after glycogen normalization. Participants then completed the same glycogen depletion protocol as performed during the normalization phase. Glycogen depletion exercise time (LOW: $84 \pm 25, A D: 88 \pm 24 \mathrm{~min}$ ) and intensity (mean power; LOW: $164 \pm 26$, AD: $161 \pm 25$ watts) were similar between treatments [12]. After glycogen depletion (GD), a second muscle biopsy was taken to confirm reductions in glycogen stores using an endpoint colorimetric assay (Cat\# MAK016; Sigma-Aldrich, St. Louis, MO, USA) as reported elsewhere [12]. There was no difference in glycogen content at BL (LOW; $467 \pm 95, \mathrm{AD} ; 472 \pm$ $109 \mu \mathrm{mol} / \mathrm{kg}$ muscle dry weight) or after GD (LOW; $207 \pm 99$, AD; $210 \pm 145 \mu \mathrm{mol} / \mathrm{kg}$ muscle dry weight) between LOW and AD [12]. Participants were then fed an isocaloric diet for the remainder of the day to elicit LOW $(3081 \pm 374 \mathrm{kcal} / \mathrm{d}, 1.5 \pm 0.1 \mathrm{~g} / \mathrm{kg} / \mathrm{d}$ carbohydrate, $1.3 \pm 0.5 \mathrm{~g} / \mathrm{kg} / \mathrm{d}$ protein, and $3.0 \pm 0.5 \mathrm{~g} / \mathrm{kg} / \mathrm{d}$ fat) or $\mathrm{AD}$ $(3086 \pm 347 \mathrm{kcal} / \mathrm{d}, 6.0 \pm 0.2 \mathrm{~g} / \mathrm{kg} / \mathrm{d}$ carbohydrate, $1.2 \pm$ $0.5 \mathrm{~g} / \mathrm{kg} / \mathrm{d}$ protein, and $1.0 \pm 0.5 \mathrm{~g} / \mathrm{kg} / \mathrm{d}$ fat) glycogen stores.

Participants returned to the laboratory the following day after a $10 \mathrm{~h}$ overnight fast. Resting metabolic rate (RMR) was measured to assess rested/fasted substrate oxidation before exercise (PRE) using an open-circuit indirect calorimetry (Parvo Medics). Participants rested in the supine position for $\sim 30 \mathrm{~min}$ before expired air was collected using an acrylic hood. The test was discontinued when 20 min of steady-state $\dot{\mathrm{VO}}_{2}$ and $\dot{\mathrm{V}} \mathrm{O}_{2}$ were recorded. After the RMR testing protocol, a pre-exercise (PRE) muscle biopsy was taken. Participants then consumed $550 \mathrm{~mL}$ of the carbohydrate drink immediately before starting the exercise bout. Participants then began cycling for $80 \mathrm{~min}$ at their target $\dot{\mathrm{VO}}_{2}$ (LOW; $65 \pm 4$, $\mathrm{AD} ; 64 \pm 3 \% \dot{\mathrm{VO}}_{2 \text { peak }}$ ). Participants consumed $300 \mathrm{~mL}$ of the carbohydrate drink at 20,40, and 60-min during exercise. Total carbohydrate ingested was $146 \mathrm{~g}$ (95 g glucose $+51 \mathrm{~g}$ fructose), consumed at an average ingestion rate of $1.8 \mathrm{~g} / \mathrm{min}$. The carbohydrate drink was prepared by the Combat Feeding Directorate (Natick, MA, USA) and contained corn-derived crystalline fructose (KRYS $\mathrm{TAR}^{\circ} 30$ 0, Tate and Lyle Sugars, London, UK), maltodextrin (MALTRIN QD ${ }^{\circ}$ M500, Grain Processing Corporation, Muscatine, IA, USA) and dextrose (CERE LOSE $^{\oplus}$, Ingredion, Westchester, IL, USA). Nutrient 
content was confirmed before use (Eurofins Food Chemistry Testing Madison, Inc, Madison, WI, USA). During exercise, respiratory gas exchange (Parvo Medics) was measured at $0,15,30,45,60$, and 75-min to assess substrate oxidation. A final biopsy was taken at the end of exercise (POST). Per study design [12], PRE and POST glycogen was lower in LOW than AD (Table 2). Following a minimum 7 day washout period, participants returned to the laboratory to complete the second arm of the study.

\section{Substrate oxidation}

Resting carbohydrate and fat oxidation was calculated as [22]:

Fat oxidation $(\mathrm{g} / \mathrm{min})=1.67 \times \mathrm{VO}_{2}(\mathrm{~L} / \mathrm{min})-1.67 \times \mathrm{VCO}_{2}(\mathrm{~L} / \mathrm{min})$

Total carbohydrate oxidation $(\mathrm{g} / \mathrm{min})=4.55 \times \mathrm{VCO}_{2}(\mathrm{~L} / \mathrm{min})-3.21 \times \mathrm{VO}_{2}(\mathrm{~L} / \mathrm{min})$

Exercise carbohydrate and fat oxidation were calculated [23]:

$$
\begin{aligned}
\text { Fat oxidation }(\mathrm{g} / \mathrm{min})= & 1.695 \\
& \times \mathrm{VO}_{2}(\mathrm{~L} / \mathrm{min})-1.701 \\
& \times \mathrm{VCO}_{2}(\mathrm{~L} / \mathrm{min})
\end{aligned}
$$

Total carbohydrate oxidation $(\mathrm{g} / \mathrm{min})=4.585 \times \mathrm{VCO}_{2}(\mathrm{~L} / \mathrm{min})-3.226 \times \mathrm{VO}_{2}(\mathrm{~L} / \mathrm{min})$.

Substrate oxidation data during exercise were previously reported [12], but are briefly presented in Table 2 of this report to highlight differences in fuel use during exercise between the two treatments. Comparison of resting substrate oxidation data between LOW and $\mathrm{AD}$ has not been previously published.

\section{Muscle biopsies}

Percutaneous muscle biopsies were conducted on the vastus lateralis using a 5-mm Bergstrom needle with manual suction while the participant was under local anesthesia (1\% lidocaine). Muscle biopies were conducted immediately before and after the glycogen depletion protocol from a single incision made in a randomly selected leg. Muscle biopsies were also conducted before and after steady-state cylcing in the contralateral leg from a single incision. The average muscle sample weight was $110 \mathrm{mg}$. Immediately after being weighed, muscle samples were snap frozen in liquid nitrogen. At the conclusion of study muscle samples were cut under liquid nitrogen and aliquoted for assessment of muscle glycogen content, activity assays, intracellcular signaling, and mRNA expression for the current and our previously published manuscript [12].

\section{Intracellular signaling}

Phosphorylation status and total protein content were determined using Western blotting. Muscle samples ( $20 \mathrm{mg}$ ) were homogenized in ice-cold homogenization buffer $(1: 10 \mathrm{w} / \mathrm{v})$ that contained $50 \mathrm{mM}$ Tris- $\mathrm{HCl}(\mathrm{pH}$ 7.5), $5 \mathrm{mM}$ Na-pyrophosphate, $50 \mathrm{mM} \mathrm{NaF}, 1 \mathrm{mM}$.

EDTA, $1 \mathrm{mM}$ EGTA, 10\% glycerol (v/v), 1\% Triton $\mathrm{X}-100,1 \mathrm{mM}$ DTT, $1 \mathrm{mM}$ benz-amidine, $1 \mathrm{mM}$ PMSF, $10 \mathrm{mg} / \mathrm{mL}$ trypsin inhibitor, and $2 \mathrm{mg} / \mathrm{mL}$ aprotinin. Samples were homogenized using a TissueLyser II with a 5-mm steel bead (Qiagen, Valencia, CA, USA). Homogenates were centrifuged for $15 \mathrm{~min}$ at $10,000 \times g$ at $4{ }^{\circ} \mathrm{C}$. Supernatant (lysate) was collected and protein concentrations were determined using $660 \mathrm{~nm}$ Protein Assay (ThermoFisher, Waltham, MA, USA). Muscle lysates were solubilized in Laemmli buffer, with equal amounts of total protein loaded $(15 \mu \mathrm{g})$ and separated by SDS-PAGE using precast Tris-HCl gels (Bio-Rad, Hercules, CA, USA). Proteins were transferred to polyvinylidene fluoride membranes and exposed to commercially available primary antibodies specific to $\mathrm{p}$-AMPK ${ }^{\text {Thr72, }}$ p-AKT ${ }^{\text {Thr473, }}$, p$\mathrm{mTOR}^{\mathrm{Ser} 2448}, \quad \mathrm{p}-\mathrm{p} 70 \mathrm{~S} 6 \mathrm{~K}^{\mathrm{Thr} 424 / 421}, \quad \mathrm{p}-\mathrm{rpS6}^{\mathrm{Ser} 235 / 236}$, AMPK, AKT, mTOR, p70S6K, and rpS6 (Cell Signaling Technology, Danvers, MA) overnight at $4{ }^{\circ} \mathrm{C}$. Secondary antibody (anti-rabbit IgG conjugate with horseradish peroxidase; Cell Signaling Technology) and chemiluminescent reagent (Pierce Biotechnology, Rockford, IL) were applied to label primary antibodies. Blots were quantified using a phosphoimager

\begin{tabular}{|c|c|c|c|c|}
\hline & \multirow[t]{2}{*}{ Group } & \multicolumn{3}{|c|}{ Steady-state cycle ergometry } \\
\hline & & PRE & DURING & POST \\
\hline \multirow[t]{2}{*}{ Glycogen ( $\mu \mathrm{mol} / \mathrm{kg}$ dry muscle $w t)$} & LOW & $217 \pm 103^{+}$ & - & $137 \pm 131^{+}$ \\
\hline & $A D$ & $396 \pm 70$ & - & $229 \pm 94^{\ddagger}$ \\
\hline \multirow[t]{2}{*}{ Carbohydrate oxidation (g/min) } & LOW & $0.04 \pm 0.03^{+}$ & $1.59 \pm 0.40^{+}$ & - \\
\hline & $A D$ & $0.12 \pm 0.02$ & $2.03 \pm 0.36$ & - \\
\hline \multirow[t]{2}{*}{ Fat oxidation (g/min) } & LOW & $0.12 \pm 0.02^{+}$ & $0.55 \pm 0.10^{+}$ & - \\
\hline & $A D$ & $0.09 \pm 0.02$ & $0.38 \pm 0.13$ & - \\
\hline
\end{tabular}
(ChemiDoc XRS; Bio-Rad) and Image Lab software

Table 2 Muscle glycogen and substrate oxidation.Adapted from Margolis et al. [12]

Values mean $\pm S D, n=11$

${ }^{+}$LOW different than AD; $P<0.05$. ' $\mathrm{POST}$ different than PRE; $P<0.05$ 
(Bio-Rad). Heat shock protein 90 (HSP90) was used to confirm equal amounts of protein were loaded per well. Phosphorylation status was normalized to its total protein. Data presented as fold change relative to BL phosphorylation for each group.

\section{mRNA expression}

Total RNA was isolated in $\sim 20 \mathrm{mg}$ muscle samples using TRIzol reagent (Thermo Fisher). RNA quantity and quality were assessed using a Nanodrop ND2000 spectrophotometer (Nanodrop, Wilmington, DE, USA). For mRNA analysis, equal amounts of total RNA (500 ng) were reverse-transcribed using the high-capacity cDNA reverse transcription (RT) kit (Applied Biosystems, Foster City, CA, USA). Reverse transcription was conducted in a $\mathrm{T} 100^{\mathrm{Ts}}$ Thermal Cycler (Bio-Rad). Amplifications were performed using a StepOnePlus Real-Time PCR System (Applied Biosystems). Samples were run in $10 \mu \mathrm{L}$ reactions in duplicate using $\operatorname{TaqMan}^{\circ}$ fast advanced master mix and commercially available TaqMan $^{\circ}$ probes (PAX7, MYOD, MYOGENIN; Applied Biosystems). All mRNA were normalized to B2M. Fold change for mRNA PRE and POST steady-state exercise were calculated using the $\Delta \Delta$ cycle threshold
$(\Delta \Delta \mathrm{CT})$ method [24] and expressed relative to individual $\mathrm{BL}$ values.

\section{Statistical analysis}

Normality for all data was confirmed using ShapiroWilk tests for dependent variables. Paired $t$-tests were used to assess differences in substrate oxidation at rest and during exercise between treatments (LOW vs. AD). Mixed-model repeated measures ANOVA was used to assess glycogen, phosphorylation status, and mRNA expression for effects of time, treatment, and their interactions. Bonferroni adjustments for multiple comparisons were performed if significant interactions were observed. All data are presented as mean \pm SD. The $\alpha$ level for significances was set at $P<0.05$. Data were analyzed using IBM SPSS Statistics for Windows Version 26.0 (IBM Corp. Armonk, NY, USA).

\section{Results}

Intracellular signaling

Independent of time, $\mathrm{p}$-AMPK ${ }^{\text {Thr172 }}$ was higher $(P<$ $0.05)$ and $\mathrm{p}-\mathrm{AKT}^{\mathrm{Thr} 473}$ was lower $(P<0.05)$ in LOW than AD (Fig. 2A, B).Regardless of treatment, pAMPK $^{\text {Thr172 }}$ was higher $(P<0.05)$ at PRE and POST compared to $\mathrm{BL}$. Independent of treatment, POST $\mathrm{p}$ -

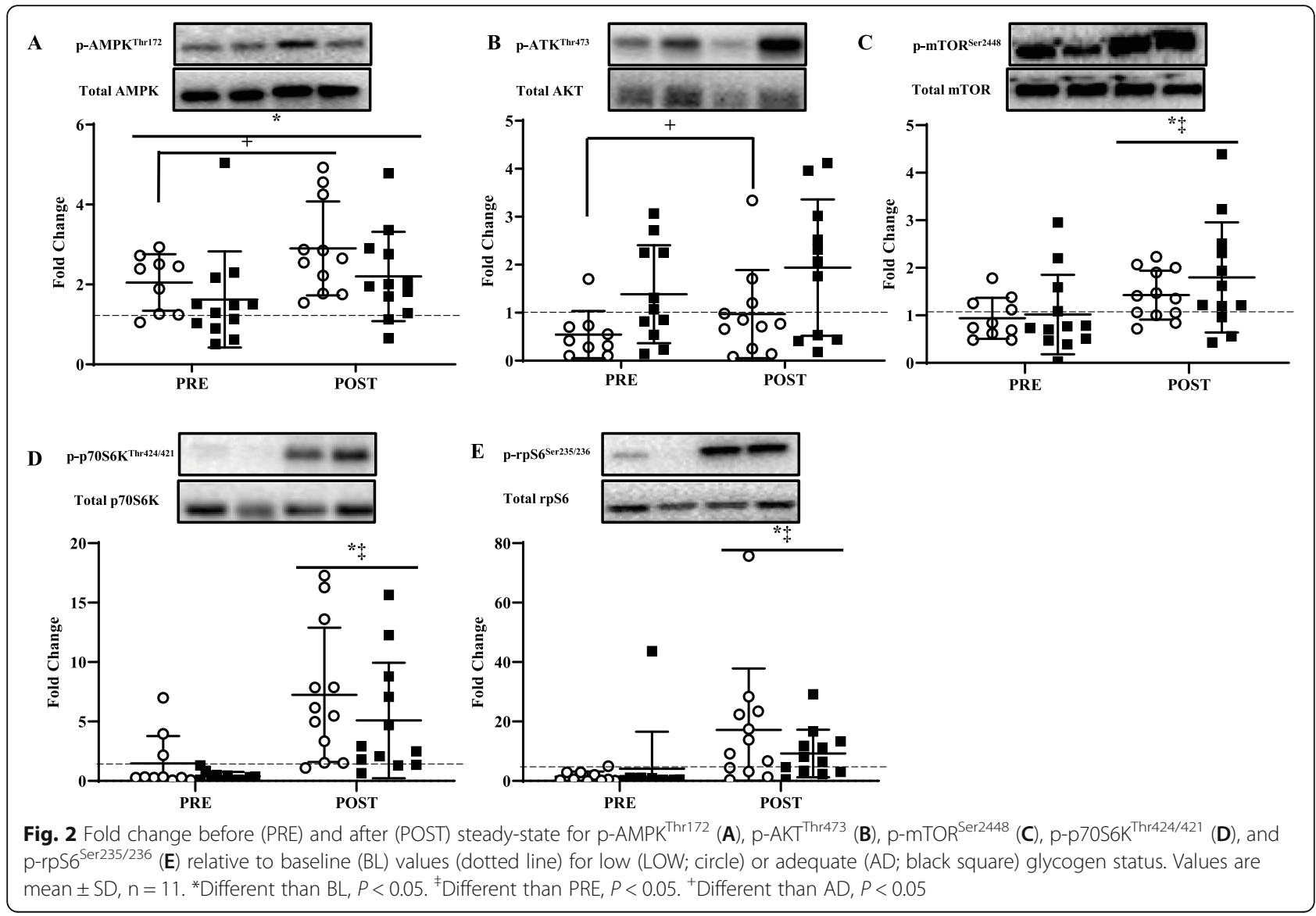


$\mathrm{mTOR}^{\mathrm{Ser} 2448}$, p-p70S6K $\mathrm{K}^{\mathrm{Thr} 424 / 421}$, and $\mathrm{p}-\mathrm{rpS6} 6^{\mathrm{Ser} 235 / 236}$ were higher $(P<0.05)$ than BL and PRE (Fig. $2 \mathrm{C}-\mathrm{E})$.

\section{mRNA expression}

Independent of time, $P A X 7$ was lower $(P<0.05)$ in LOW than AD (Fig. 3A). PRE MYOD was lower $(P<0.05)$ in LOW than AD (Fig. 3B). POST MYOD in LOW and AD were higher $(P<0.05)$ than PRE, with no difference between group. Independent of time, MYOGENIN was lower $(P<0.05)$ in LOW than AD (Fig. $3 C)$.

\section{Discussion}

The primary results from this study were that despite differences in AMPK and AKT phosphorylation, initiating aerobic exercise with low glycogen did not affect downstream mTORC1 signaling compared to adequate glycogen. Though no differences in mTORC1 signaling were observed, lower glycogen at the onset of exercise reduced the expression of myogenic regulatory factors, PAX7, MYOD, and MYOGENIN. Reductions in myogenesis may indicate lower post-exercise muscle recovery.

The most novel finding from the current study was that performing aerobic exercise with low muscle glycogen content resulted in lower PAX7 and MYOGENIN expression before and after exercise compared to adequate glycogen. Additionally, low glycogen status reduced $M Y O D$ expression under resting fasted conditions compared to adequate glycogen. However, following aerobic exercise and carbohydrate consumption, MYOD expression was increased compared to pre aerobic exercise, and was not different between groups. These mediators of myogenesis are integral to the activation of myogenic precursor cells (e.g., satellite cells), facilitating proliferation and differentiation of myoblasts into myotubes; a primary function required for muscle repair and regeneration $[25,26]$. As such, reductions in the transcription of these myogenic-related genes may impede muscle recovery from exercise [27]. It appears that differences in PAX7, MYOD, and MYOGENIN between LOW and $\mathrm{AD}$ were primarily driven by lower expression at PRE. The PRE measurement was taken $24 \mathrm{~h}$ after participants completed glycogen depleting exercise followed by high carbohydrate, low-fat (63\% carbohydrate or $24 \%$ fat) or low carbohydrate, high-fat (16\% carbohydrate and $71 \%$ fat) refeeding diet to achieve AD or LOW muscle glycogen, respectively. Whether low glycogen availability, increased fat intake, or a combination of both caused lower myogenesis in LOW compared to AD is not clear, because exercise and diet manipulation were used to manipulate glycogen availability in both treatments.

Given the differences in AKT between treatments, we hypothesize that lower phosphorylation of AKT in LOW facilitated lower myogenic regulatory factor expression compared to AD. AKT is an important upstream regulator of myogenesis $[28,29]$. Overexpression of AKT in $\mathrm{C} 2 \mathrm{C} 12$ myoblasts induces myogenic differentiation by increasing myogenic regulator factor expression to simulate myotube formation, while inhibition of AKT decreases myogenesis [28-30]. In the current study, alterations in myogenesis via AKT were likely through downstream activation of GSK-3 $\beta$ [31]. GSK-3 $\beta$ regulates glycogen stores through inhibition of glycogen synthase activity, thereby blunting the conversion of glucose to glycogen within muscle [32]. Lower phosphorylation of AKT, similar to that observed in the present study, increases GSK-3 $\beta$ activity resulting in reduced glycogen synthesis within skeletal muscle [21]. Beyond regulation of glycogen content, in vitro experiments have reported that GSK-3 $\beta$ is an AKT intermediate and regulator of myogenesis [31]. Increased insulin-mediated phosphorylation of AKT deactivates GSK-3 $\beta$, resulting in increased expression of myogenic regulatory factors to facilitate myogenesis [31, 33]. We suspect higher phosphorylation of AKT in AD PRE and POST mediated the higher expressions of PAX7, MYOD, and MYOGENIN compared to LOW.

Increased fat intake post exercise may also have contributed to lower expression of myogenic regulatory factors in LOW compared to AD. Differentiating C2C12 myoblasts in medium that contained fatty acids resulted
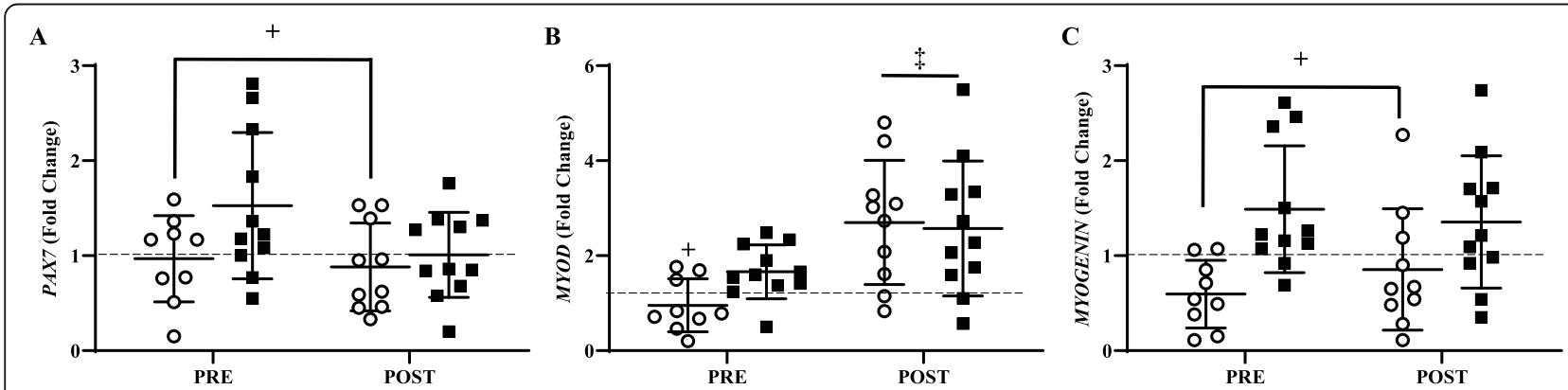

Fig. 3 Fold change before (PRE) and after (POST) steady-state for PAX7 (A), MYOD (B), and MYOGENIN (C) relative to baseline (BL) values (dotted line) for low (LOW; circle) or adequate (AD; black square) glycogen status. Values are mean $\pm S D, n=11$. *Different than $B L, P<0.05$. ${ }^{*}$ Different than PRE, $P<0.05 .{ }^{+}$Different than $\mathrm{AD}, P<0.05$ 
in reduced myotube formation compared to control [19]. Reduced myotube formation was the result of lower PAX7, MYOD, and MYOGENIN in the lipid-enriched media compared to control [19]. In addition to lower expression of myogenic regulatory factors, the same in vitro experiment [19] reported higher expression of CPT1 and FAT; genes associated with adipogenesis. Those observations agree with our previous findings, where we reported increased expression of molecular regulators of fatty acid uptake and transport with higher fat intake [12]. Together these results may suggest that acute increases in fatty acid availability upregulates expression of genes associated with adipogenesis while genes regulating myogenesis are reduced.

There was no effect of glycogen content on phosphorylation status of the mTOR, p70S6K, and rpS6. Several previous human studies have examined the effect of glycogen content on muscle protein synthesis and anabolic signaling $[13,16,17,34]$. Some report either a decrease $[13,17]$ or no difference $[16,34]$ in muscle protein synthesis or mTORC1 signaling when initiating exercise with low glycogen content. The discrepancies between studies may be partially explained by differences in exercise modality (resistance vs. aerobic vs. high intensity interval exercise), energy state (energy balance vs. energy deficit), and fed state (fed vs. fasted). Another factor that may contribute to variable results across studies is the severity by which muscle glycogen is lowered. Hammond et al. [16] hypothesized that muscle glycogen must be $<100 \mu \mathrm{mol} / \mathrm{kg}$ dry weight to negatively affect the anabolic response to exercise. Indeed, Impey et al. [17] reported lower p70S6K activity post exercise when muscle glycogen content was reduced to < $100 \mu \mathrm{mol} / \mathrm{kg}$ dry weight, and reported that the severity of the decline in p70S6K activity was associated with glycogen content. Our data agree with this hypothesis, as mTORC1 signaling was maintained when aerobic exercise was initiated with muscle glycogen concentrations of $\sim 200 \mu \mathrm{mol} / \mathrm{kg}$ dry weight in LOW compared to $\sim$ $400 \mu \mathrm{mol} / \mathrm{kg}$ dry weight in AD.

Results from this study provide novel insight into the effects of glycogen availability on post-exercise mTORC1 signaling and myogenesis in muscle. However, a limitation of our study was the lack of serial blood sampling during exercise. Not assessing the changes in glucose, insulin, and free-fatty acids concentrations during exercise prohibits us from examining the potential impact of possible differences in circulating substrates between treatments on skeletal muscle adaptations. Additionally, due to limited sample availability we were not able to measure GSK-3 $\beta$ to assess if its phosphorylation status was in agreement with our AKT data. Though GSK-3 $\beta$ was not measured in the current study, it stands to reason that differences in glycogen content between treatments would be the result of differences in molecular pathways governing glycogen synthesis. Finally, results of the current study should be interpreted in the context in which they were collected. Our results show acute differences in markers of myogenesis when exercise is initiated with low or adequate glycogen stores. The impact of these acute signaling and transcriptional modifications on long term training adaptations effecting muscle mass, phenotype, and physical performance are unclear.

\section{Conclusion}

In conclusion, initiating aerobic exercise with low muscle glycogen increased phosphorylation of AMPK and decreased phosphorylation of AKT compared to adequate glycogen. Despite differences in upstream targets, low glycogen content did not affect insulin-dependent mTORC1 signaling, but did result in reduced expression of myogenic regulatory factors. Lower expression in key myogenic regulator factors suggest that muscle recovery from exercise may be reduced when exercise is performed with low muscle glycogen.

\section{Abbreviations}

FAT: Fatty acid translocase; CPT1a: Carnitine palmitoyl transferase 1a; HADHA: Hydroxyacyl-CoA dehydrogenase; PDH: Pyruvate dehydrogenase; mTORC1: Mechanistic target of rapamycin complex 1; MRDC: Medical Research and Development Command; LOW: Low glycogen; AD: Adequate glycogen; BL: Baseline; PRE: Pre exercise; POST: Post exercise

\section{Acknowledgements}

The authors wish to acknowledge Dr. Andrew Young for his critical review of this manuscript, and the volunteers that participated in this research experiment. The authors acknowledge our medical oversight team for their support of this study. Most importantly, we wish to sincerely thank Dr. Nicholas Barringer and Mr. Anthony Karis from the US Army Research Institute of Environmental Medicine, and Ms. Danielle Anderson from the Combat Feeding Directorate for their contributions to the project.

\section{Authors' contributions}

LMM and SMP designed research; LMM, MAW, CCW, CTC, NEM, and AHM performed research; LMM, MAW, CCW, CTC, NEM, and AHM analyzed data; LMM and SMP interpreted results; LMM and SMP prepared tables and figures; LMM drafted the manuscript. All authors read and approved final manuscript.

\section{Funding}

This work was supported by Defense Health Program/Military Operational Medicine Research Program.

Availability of data and materials

All extracted data are presented in this manuscript. The corresponding author may be contacted for any data requests or questions.

\section{Declarations}

Ethics approval and consent to participate

The investigators adhered to the policies for protection of human subjects as prescribed in Army Regulation 70-25, and the research was conducted in adherence with the provisions of 32 CFR part 219. The opinions or assertions contained herein are the private views of the authors and are not to be construed as official or as reflecting the views of the Army or the Department of Defense. Any citations of commercial organizations and trade names in this report do not constitute an official Department of the Army endorsement of approval of the products or services of these organizations. All participants provided informed written consent prior to starting data collection. 


\section{Consent for publication}

No individuals' personal data were included in this manuscript.

\section{Competing interests}

L.M.M., M.A.W., C.C.W., C.T.C., N.E.M., A.H.M., and S.M.P have no competing interests associated with this study.

\section{Received: 20 May 2021 Accepted: 22 June 2021}

Published online: 10 July 2021

\section{References}

1. Purdom T, Kravitz L, Dokladny K, et al. Understanding the factors that effect maximal fat oxidation. J Int Soc Sports Nutr. 2018;15:3.

2. Arkinstall MJ, Bruce CR, Clark SA, et al. Regulation of fuel metabolism by preexercise muscle glycogen content and exercise intensity. J Appl Physiol. 1985;2004(97):2275-83.

3. Hargreaves M, McConell G, Proietto J. Influence of muscle glycogen on glycogenolysis and glucose uptake during exercise in humans. J Appl Physiol. 1985;1995(78):288-92.

4. Hearris MA, Hammond KM, Seaborne RA, et al. Graded reductions in preexercise muscle glycogen impair exercise capacity but do not augment skeletal muscle cell signaling: implications for cho periodization. J Appl Physiol. 1985;2019(126):1587-97.

5. Impey SG, Hearris MA, Hammond KM, et al. Fuel for the work required: a theoretical framework for carbohydrate periodization and the glycogen threshold hypothesis. Sports Med. 2018:48:1031-48.

6. Arkinstall MJ, Tunstall RJ, Cameron-Smith D, et al. Regulation of metabolic genes in human skeletal muscle by short-term exercise and diet manipulation. Am J Physiol Endocrinol Metab. 2004;287:E25-31.

7. Cameron-Smith D, Burke LM, Angus DJ, et al. A short-term, high-fat diet upregulates lipid metabolism and gene expression in human skeletal muscle. Am J Clin Nutr. 2003;77:313-8.

8. Pilegaard $\mathrm{H}$, Keller $\mathrm{C}$, Steensberg A, et al. Influence of pre-exercise muscle glycogen content on exercise-induced transcriptional regulation of metabolic genes. J Physiol. 2002;541:261-71.

9. Pilegaard H, Osada T, Andersen LT, et al. Substrate availability and transcriptional regulation of metabolic genes in human skeletal muscle during recovery from exercise. Metabolism. 2005;54:1048-55.

10. Peters SJ, Harris RA, Wu P, et al. Human skeletal muscle pdh kinase activity and isoform expression during a 3-day high-fat/low-carbohydrate diet. Am J Physiol Endocrinol Metab. 2001;281:E1151-8.

11. Stellingwerff T, Spriet LL, Watt MJ, et al. Decreased pdh activation and glycogenolysis during exercise following fat adaptation with carbohydrate restoration. Am J Physiol Endocrinol Metab. 2006;290:E380-8.

12. Margolis LM, Wilson MA, Whitney CC, et al. Exercising with low muscle glycogen content increases fat oxidation and decreases endogenous, but not exogenous carbohydrate oxidation. Metabolism. 2019;97:1-8.

13. Howarth KR, Phillips SM, MacDonald MJ, et al. Effect of glycogen availability on human skeletal muscle protein turnover during exercise and recovery. J Appl Physiol. 1985;2010(109):431-8.

14. Larsen MS, Holm L, Svart MV, et al. Effects of protein intake prior to carbohydrate-restricted endurance exercise: a randomized crossover trial. J Int Soc Sports Nutr. 2020;17:7

15. Gillen JB, West DWD, Williamson EP, et al. Low-carbohydrate training increases protein requirements of endurance athletes. Med Sci Sports Exerc. 2019;51:2294-301.

16. Hammond KM, Impey SG, Currell K, et al. Postexercise high-fat feeding suppresses p70s6k1 activity in human skeletal muscle. Med Sci Sports Exerc. 2016:48:2108-17.

17. Impey SG, Hammond KM, Shepherd SO, et al. Fuel for the work required: a practical approach to amalgamating train-low paradigms for endurance athletes. Physiol Rep. 2016;4:e12803.

18. Stephens FB, Chee C, Wall BT, et al. Lipid-induced insulin resistance is associated with an impaired skeletal muscle protein synthetic response to amino acid ingestion in healthy young men. Diabetes. 2015;64:1615-20.

19. Hsueh TY, Baum Jl, Huang Y. Effect of eicosapentaenoic acid and docosahexaenoic acid on myogenesis and mitochondrial biosynthesis during murine skeletal muscle cell differentiation. Front Nutr. 2018:5:15.

20. Conejo R, Valverde AM, Benito M, et al. Insulin produces myogenesis in c2c12 myoblasts by induction of nf-kappab and downregulation of ap- 1 activities. J Cell Physiol. 2001;186:82-94.
21. Manning BD, Toker A. Akt/pkb signaling: navigating the network. Cell. 2017; 169:381-405.

22. Ferrannini $\mathrm{E}$. The theoretical bases of indirect calorimetry: a review. Metabolism. 1988;37:287-301.

23. Peronnet $F$, Massicotte $D$. Table of nonprotein respiratory quotient: an update. Can J Sport Sci. 1991;16:23-9.

24. Pfaffl MW. A new mathematical model for relative quantification in real-time rt-pcr. Nucleic Acids Res. 2001;29:e45.

25. Relaix F, Zammit PS. Satellite cells are essential for skeletal muscle regeneration: the cell on the edge returns centre stage. Development. 2012; 139:2845-56.

26. Yin H, Price F, Rudnicki MA. Satellite cells and the muscle stem cell niche. Physiol Rev. 2013;93:23-67.

27. Caldow MK, Thomas EE, Dale MJ, et al. Early myogenic responses to acute exercise before and after resistance training in young men. Physiol Rep. 2015;3:e12511

28. De Angelis L, Balasubramanian S, Berghella L. Akt-mediated phosphorylation controls the activity of the $y$-box protein msy3 in skeletal muscle. Skelet Muscle. 2015;5:18.

29. Jiang BH, Aoki M, Zheng JZ, et al. Myogenic signaling of phosphatidylinositol 3-kinase requires the serine-threonine kinase akt/ protein kinase b. Proc Natl Acad Sci USA. 1999;96:2077-81.

30. Briata P, Lin WJ, Giovarelli M, et al. Pi3k/akt signaling determines a dynamic switch between distinct ksrp functions favoring skeletal myogenesis. Cell Death Differ. 2012;19:478-87.

31. Litwiniuk A, Pijet B, Pijet-Kucicka M, et al. Foxol and gsk-3beta are main targets of insulin-mediated myogenesis in c2c12 muscle cells. PLoS ONE. 2016;11:e0146726.

32. Beurel E, Grieco SF, Jope RS. Glycogen synthase kinase-3 (gsk3): regulation, actions, and diseases. Pharmacol Ther. 2015;148:114-31.

33. van der Velden JL, Langen RC, Kelders MC, et al. Inhibition of glycogen synthase kinase-3beta activity is sufficient to stimulate myogenic differentiation. Am J Physiol Cell Physiol. 2006:290:C453-62.

34. Camera DM, West DW, Burd NA, et al. Low muscle glycogen concentration does not suppress the anabolic response to resistance exercise. J Appl Physiol. 1985;2012(113):206-14.

\section{Publisher's Note}

Springer Nature remains neutral with regard to jurisdictional claims in published maps and institutional affiliations.
Ready to submit your research? Choose BMC and benefit from:

- fast, convenient online submission

- thorough peer review by experienced researchers in your field

- rapid publication on acceptance

- support for research data, including large and complex data types

- gold Open Access which fosters wider collaboration and increased citations

- maximum visibility for your research: over $100 \mathrm{M}$ website views per year

At $\mathrm{BMC}$, research is always in progress.

Learn more biomedcentral.com/submissions 